\title{
UNDERSTANDING THE EFFICACY OF TELECONSULTATION IN ASSUAGING ABUSE AGAINST INDIAN WOMEN DURING COVID-19 OUTBREAK
}

\author{
Debashrita Dey \\ Institute Fellow (PhD), Department of Humanities and Social Sciences \\ Indian Institute of Technology Patna (India) \\ deydebashrita@gmail.com \\ Priyanka Tripathi \\ Associate Professor of English, Department of Humanities and Social Sciences \\ Indian Institute of Technology Patna (India) \\ priyankatripathi@iitp.ac.in
}

\begin{abstract}
Covid-19 pandemic has impacted societal well-being in different and interacting contexts and its long duree consequences on human health, both biological and psychological serves to be a key element in the public discourse. The "pandemic-lockdown" in the Indian context made the health and social faultlines existing in the country hypervisible making one question the 'normal' we were existing with, in the pre-Covid times. As the virus took its toll on the fragile health system, nearly crushing it, individual's rights to a safe and dignified life got threatened in the private spaces. The psycho-social effects of the pandemic arising from the exploitation in the public/private domains can be recognized as infringements with severe and sustained negative repercussions on the vulnerable sections of society. While analysing the intersecting vulnerabilities on varied fronts, another intense predicament related to women and elderly abuse in the (un)safe homely space awaits address and redressal. The nature of stressors underlying such abuse reflects on a complex interplay among several factors at an individual, community, and collective levels. The use of digital platforms, social media sites, and teleconsultation in moments of unprecedented crisis suggests towards creating an alternative paradigm for addressing the psychosocial dimension of the pandemic that lies intertwined with the "underlying injustices and social conditions". In the backdrop of the Covid context, this paper would analyse how teleconsultation and telepsychiatry became an apparent channel to ensure health based services and extend support and safety to those victims and survivors of family abuse who remain marginalized in the society on sexist and ageist constructs.
\end{abstract}

Keywords: pandemic-lockdown, domestic abuse, elderly abuse, teleconsultation, telepsychiatry

\section{INTRODUCTION}

The first wave of the Covid-19 pandemic that hit the world in 2020 nearly affecting 203 countries had posed deep challenges to our physical and psychological health (Bhattacharyya, Dastidar \& Sikdar, 2021). While every nation was trying to grapple with its crippling aftermath, another subsequent wave severely impacted public health and simultaneously increased the fatality rate. The overburdened state of the health department, the lack of preparedness to handle the exponential rise in positive cases and the increased rate of the virus transmission posed an imminent threat to some countries during the calamitous second wave (Asrani, Eapen, Hassan \& Sohal, 2021). By mid of April 2021, the SARS-CoV-2 virus has nearly affected 140 million people and claimed 3 million lives worldwide. Alongside, it has adversely affected the global economic growth, pushing countries to the brink of recession, living numerous unemployed, and initiating mass poverty. The healthcare industry has been one of the potent sectors facing a severe setback due to the paucity of medical health experts, anti-viral drugs, intensive care units, hospital beds, and other relevant requirements (Gautam et al., 2021). The public healthcare departments have especially been overburdened with the surge in Covid cases and casualties and the most critical fallout has been the shortage of oxygen supply which has exacerbated the situation further in some 
countries. With a significant dearth of medical resources and staff, the countries in the Global South struggled to flatten the soaring Covid curve in their individual nations and have been able to curb the unprecedented spread of the virus, are now focusing to deal with the social and economic consequences of the pandemic. However, India happens to be one such country that surfaced as a hotbed for the successive second wave of the virus in 2021 and reports of the tolling deaths, the heartwrenching images of the burning pyres, the varied tales of experienced horror revolving around patients gasping for breath due to the lack of oxygen makes one realizes about the catastrophe that has unfolded in the country in the past few months (Sonawane, 2021).

Communication plays a fundamental role in generating and re-generating shared meanings, and the implementation of the "constitutive model of communication" (Thompson, Dorsey, Miller \& Parrott, 2003, p. 11) that addresses particular purposes has hold definite relevance in the Covid crisis. Emerging as a practical discipline, communicative interactions has revealed the underlying complexities of the present times that centres around the physicality of the Covid disease and the "materiality of bodies" (Thompson et al., 2003, p. 11) along with the varied meanings of embodied sufferings/trauma experienced by patients, their families, the care-givers and the health professionals rendering their services. While conceptualizing 'health' one should discern the psychological facets that remain integrated with the physical aspects, thus making communication important for a better understanding of health-related discourses and the concerning tensions enveloping it. The global crisis did have an adverse effect on the mental health of the masses also and remains entwined within varied grounds- the increase in anxiety at the horrific outbreak of the virus, the emotional trauma and the social stigma associated with Covid deaths, the alarming rise in cabin fear syndrome ${ }^{1}$ due to social distancing and lockdown measures, the escalation in psychological threat experienced by the vulnerable sections comprising elderly citizens, women, children, underprivileged classes. As health communication focuses on the effective usage of communication strategies to provide services, inform people and procure personal narratives, it helps the medical professionals to distinguish between the pathological effect of the disease and the concomitant experience of the illness by the patient and his/her family that reflect on disconcerting realities within individualized contexts. As sociologist Kathy Charmaz observes that "Suffering is of the self and it is social" (Charmaz, 1999, p. 365) it becomes significant to take into consideration the cognitive and the emotional journey of those people who have been directly/indirectly affected by the pandemic for mitigating the wounded identities of the sufferers. The effectiveness of communication has represented the commonality of experiences, especially the marginalized sections thus highlighting the multiplicity of voices and selves in the hour of crisis that lurk beneath the epidemiological understanding of the disease. To influence social behaviour and foster change has been the ultimate goal of health communication, and during the Covid19 pandemic communication based interventions and meaningful interaction has addressed needs, reduced risks and provided e-health treatment to patients affected by the disease and numerous others undergoing psychological disease.

While exploring the epidemiological consequences of the "pandemic-lockdown" (Hans, Kannabiran, Mohanty, \& Pushpendra, 2021, p. 1) in India, one underlying dimension has emerged as a viable concern to both medical and academic researchers is the psycho-social health of individuals. As we entered a critical juncture in history in 2020 battling with an invisible yet powerful enemy, adapting ourselves to the 'new-normal' and confining ourselves to our rooms, the virus took a definite toll on the mental well-being of individuals. The home isolation, the restriction on social life, the lingering uncertainty, the fear of contagion, the harshness of events triggered by the onset of the pandemic, the entrapping media representation of the infection rate did have a negative impact on the subjective mental health of mankind (Paredes, Apaolaza, Robin, Hartmann, \& Yañez-Martinez, 2020). To restrain the deadly spread of the infection, the lockdown was considered to be an effective approach and the "Stay Home, Stay Safe" catchline vehemently underlined how staying indoors and adhering to healthy protocols can aid in keeping the virus away. However, a pertinent concern 
regarding how 'safe' the home is for the vulnerable sections of society seeks an understanding. Considered to be a safe haven, the home is also the site of a heightened risk of abuse for women, children (Gandhi, 2020), and elderly people (Chang \& Levy, 2020) largely affecting their collective psyche. Thus, the virus emerged as an influential indicator unravelling the deep-rooted complexities and exploitation that breed in the domestic setting and envelop the individual, the family, and the society at large (Vahali, 2021). Violence pertaining to gender and ageism saw a distinct rise during the pandemic as women and aged people became the primary targets of varied kinds of abuse owing to increased unemployment, expenditure, alcoholism, heightened sense of frustration, and other legitimate causes. In India, the psychological stress and physical aggression experienced during the nationwide lockdown by the dependent and oppressed 'other' (constituting housewives, children, and aged beings) brings to the forefront the different dimensions of power struggle in the familial spaces. The National Commission for Women received 607 cases of domestic abuse in 2019 which considerably rose to 1,477 between the span of March to May 2020 (Tomar \& Mohanty, 2020), thus indicating the sheer plight of Indian women within the households. While women became more prone to domestic violence and reported cases rose by more than 2.5 times (Tomar \& Mohanty, 2020), the social isolation enforced during the pandemic has been termed as one of the main "predictors of elder abuse" (Han 2020, 1386) as it considerably disrupted the support network systems for the fragile beings. Surveys conducted by Agewell Foundation (Pandit, 2020) and HelpAge India ("Elderly, differently-abled, widows to get 3 months' pension in advance", 2020) across different cities in India ahead of 15 June 2020 commemorating the World Elder Abuse Awareness Day, reflected that nearly $71 \%$ of elderly respondents have reported increased abuse in the lockdown period. Hence, besides addressing the "shadow pandemic" 2 (Tomar \& Mohanty, 2020; Lal, 2020), there lies a pressing need to recognize the different types of mistreatment occurring concurrently on aged citizens within a particular dyad across the nation.

This paper would explore how there has been a recorded increase in the incidence of telecommunication and teleconsultation in
India by numerous women and older people suffering psycho-social distress during the lockdown. The reported cases help us to reflect on the fundamental predicament of gendered and age-related violence in the country that gets overshadowed by the horror of the Covid outbreak. While living through the reality of burning pyres, oxygen crisis, and alarming rise in cases, it is also important to recognize the pertinent social problem related to exploitation in the domestic fronts and how the pandemic has further deprived the marginalized beings of their basic rights to a dignified and secured life.

As the pandemic has affected mankind on varied grounds and cannot be simply limited to the category of a public health crisis (The Elders, 2020) it has initiated the requirement for subsequent thinking and intervention that would ensure global collective effort to readdress both physical and psychological abuse occurring in the domestic spaces. Since, physical distancing protocols, the stringent lockdown measures, and the prolonged confinement at homes rendered it impossible for the victim of neglect and abuse to seek the necessary legal aid or community help, an efficient way of tackling the vital problem was through telemedicine, online counseling and tracking apps- where communication was deemed beneficial for exploring the discursive effects of the pandemic and promote health advocacy in its holistic sense. With digital technologies efficiently paving the way for increased use of "information technology" along with "data-driven systems" (Eren \& Webster, 2016, p. ix) in healthcare and medical practices, telemedicine in such crucial moments of an absolute breakdown of the health machinery has enabled virtual consultation, counseling, and telecare for not only patients but also for those facing victimization in the hands of their own family. In a traditional structure, like India where most of the patients prefer a face-to-face consultation with the doctor or medical expert for any health or psychological difficulties, the Covid situation has made the climate favorable for the thriving of teleconsultation and e-health services. Despite the country witnessing the advent of telemedicine in 2001 which was a pilot project spearheaded by the Indian Space Research Organization (ISRO), the concept remained nascent due to insufficient resources, lackadaisical approach 
related to policymaking at the different administrative levels, poor acceptance among patients and lukewarm response from medical professionals.

Evident questions were also raised on the quality and effectiveness of the care services that were being provided through the telephonic/virtual platforms and patients were worried about the confidentiality of their problems. As strict protocols to deal with patient's grievances regarding misconduct, breach of privacy, poor standard of service or negligence were absent, the teleconsultation practice remained an alien concept in the Indian minds (Dinakaran, Manjunatha, Kumar $\&$ Math 2021). The Covid emergency in the nation however actuated the usage of telemedicine for expanding the access to health information and enabling communicative intervenetion for reaching out to intended patients/victims as physical consultation was largely impacted due to the lockdown measures. With women across different age-groups becoming the prime targets of domestic violence during the pandemic induced lockdown, cases often went unregistered and unevaluated due to the enforced isolation norms. A considerable share of violence against women also remained invisible in the pandemic scenario as the victims feared retaliation by the perpetrator along with the limited contact with their informal support groups (like friends and relatives) and restricted access to the police (What crime and helpline data say about the impact of the COVID-19 pandemic on reported violence against women and girls, 2020).

As reports of different forms of abuse along with psychological distress escalated, it became necessary to regularize the consultation services and follow-up sessions which could only be rendered possible through telecommunication. Popularizing telemedicine could also effectively minimize inequities and deal with the barriers to access, thus ensuring timely help to those in dire need of safety and counselling.

To deal with the immediate crisis situation and to create a receptive environment for understanding the nature of suffering- both physical and emotional, the Medical Council Act, 1956 was amended by the Medical
Council of India (MCI) who published the Telemedicine Practice Guidelines, 2020 that came into effect from May 12, 2020 (Aneja \& Arora, 2021). Thus, a paradigm shift has been distinctly visible from the physical check-ups in the hospitals/clinics to the reliance upon the evolving telehealth facilities which has effectively extended the required care and support to those suffering from the disease or from one of the major adjunct of the virus- the familial abuse. This has effectively sensitised the health communication practitioners about the interrelated experiences of the body, mind and the society that became pronounced during the pandemic, thereby promoting a holistic understanding of 'health' and catering for both the subjective and the objective dimensions of well-being (Thompson et al., 2003). Thus, teleconsultation services served as a vital instrument mitigating the gaps in legislative actions and ensuring cost-effective, practical and safe services to those suffering silently on varied grounds.

Research conducted in the wake of the Covid19 pandemic has shown that telehealth facilities have made care services more accessible to people and its widespread implementation and acceptance has proved its efficiency in providing the required aid. Its vital role in dealing with 'shadow pandemic' and geriatric abuse has ensured for the detection and addressal of cases even when it became difficult to provide help physically. Several government and community helpline numbers specifically dealing with genderbased violence remained active at the juncture of global crisis, catering to the grievances and assuring the security of the Indian women. The following sections of the article would explore how the country has witnessed a rise in the usage of teleconsulation services to promote physical and emotional well-being during the uncertain times and create a support network that would enable a safer existence.

\subsection{LITERATURE REVIEW}

The pandemic has increased the risk of physical and psychological threat for younger and elder women alike in the country and various studies have revealed a glaring reality concerning their well-being. The violence against women that accompanied the government imposed lockdown was termed as the "shadow pandemic" (United Nations 
Women, 2020) and different states across India saw a persistent rise in crimes within the domain of the house ranging from domestic abuse, rapes, sexual assault, emotional harassment and others. Saravana Ravindran and Manisha Shah in the article Unintended Consequences of Lockdowns: Covid-19 and the Shadow Pandemic observes that the National Commission of Women recorded a drastic surge in the number of received complaints pertaining to domestic abuse (2020). With the lingering internalization of the gender menace where a man beating and assaulting his mother/wife/daughter and female relatives is normalized in the regressively patriarchal structure, it becomes further difficult to address such critical issues. This also aggravates the greater chances of abuse as the men feel their aggressive outburst to be a justified action and the female victims passively encounter it as their destined experience.

The existing literature emphasizes how women regardless of age has been exploited in a multidimensional manner and the pandemic has posed more difficulties for the elderly and widowed women who are the most vulnerable groups in the society. Sutirtha Bandyopadhyay and Bipasha Maity in their book chapter, "Covid-19 Pandemic: Implications for Widowed and Elderly Women in India" in Covid-19 Pandemic: Implications for Widowed and Elderly Women in India (2021) mention how widowhood and age accentuates the state of burdenhood and dependency for a woman and in the context of the pandemic it becomes important to analyse how these women have been subjected to abuse and deprivation by their family and kin. The helpline data collected by United Nations Office on Drugs and Crimes from 34 countries reported that more women sought for help through emergency numbers as the restrictive measures exacerbated their sufferings. In India, nearly 50 helpline numbers were started across the states by women welfare departments, police and NGOs to alleviate the misery of those women facing domestic violence (Coronavirus lockdown | Over 50 helplines set up across India to help women facing domestic violence, 2020). The chairperson of National Commission for Women, Rekha Sharma observed in an interview by The Hindu that they have started the helpline number initiative where women facing abuse can register a complaint through a Whatsapp message as this medium was easier to operate than sending emails. She further stated that after seeking the necessary information from the victim, the local police along with a counsellor will intervene to provide her the required help. The Department of Psychiatry, NIMHANS has also laid down some important guidelines for asking questions to a woman who has experienced familial abuse and how support can be extended through teleconsultations. Several newspaper and journal articles reflect on the active measures that has been undertaken at different levels of the administrative body in the country to channelize assistance through the means of telecommunication to women who fell prey to abusive treatments during the pandemic.

\subsection{METHODOLOGY}

This article significantly makes use of secondary data collected from different newspaper articles, journals and online news portals. Primary data has been procured from government sources like Longitudinal Ageing Study in India (LASI), Wave-1(2020) and other sources like Telemedicine Practice Guideline: Enabling Registered Medical Practitioners to Provide Healthcare Using Telemedicine (2020), Mental Health in the times of COVID19 Pandemic: Guidance for General Medical, National Institute of Mental Health \& Neurosciences (2020) and data gathered from World Health Organization.

\section{3 'Shadow Pandemic' and the Rise in Telecommunication}

There has been an intrinsic relation between domestic abuse and mental health (Sanderson, 2008) and the pandemic has reinforced it by exposing the psychobiological impact of the increased exploitation on women during the lockdown in the country. The traumatizing pattern of experience not only overrules the rights and freedom of a woman but has interrelated effects on her physical and emotional well-being ( $\mathrm{O}^{\prime}$ Leary \& Maiuro, 2001). In Indian society, domestic abuse has been a pervasive problem and the initial months of the lockdown witnessed a surge in the complaints from victims and the figures were distinctly more than the past cases recorded in the last ten years (Radhakrishnan, Sen \& Singaravelu, 2020). The different types of crime against women have largely 
increased by $21 \%$ in the nation with states like Delhi, Punjab, Haryana, Uttarakhand, Telangana reporting the highest cases of domestic violence (Das, Das \& Mandal, 2020; "Domestic violence cases in India on the rise during lockdown, says report",2020). With a majority of the people being restricted in their homes, women faced a heightened risk of ill-treatment from their husbands and family and the special women help desk claimed that from March to August 2020, more than 600 cases of physical and mental abuse were registered. The pandemic has largely affected both housewives and working women and the increase in their burden has been categorically diverse in nature (Kumar \& Rana, 2020). Primarily, known to be a caregiver in the Indian family, women were further pushed into the realm of domestication and gendered social norms resulting in physical abuse, emotional abandonment, threatening/ spiteful behaviors, and restriction of personal freedom. With household stress intensifying due to the economic pressure, disruption of livelihoods, and loss of employment, women often became the acute targets of aggression in the patriarchal structure. As per as special women's help desk since 24 March 2020, more than 600 cases of mental and physical tortures have been recorded against husbands (due to taking drugs and consumption of alcohol) and family members. When the governmentimposed limitations on mobility, it did decrease the chances of contracting the disease but increased the plight of women facing abuse as with the presence of the perpetrators at home, they often could not raise a complaint or seek the required help observed the chairperson of the National Commission of India, Rekha Sharma ("Domestic violence on the rise during lockdown, 69 complaints since 24 March: NCW", 2020). Also, despite the presence of shelter homes and the availability of helpline numbers nationwide, the police force or voluntary organizations could not extend help as their reach was highly curtailed by the lockdown. In fact, cases for domestic violence against women are lodged in lower courts, and during the peak of the virus in the country, the courts were only functioning for emergency hearings (Ratnam, 2020). Another appalling situation that has surfaced in the recent phase, is "obstetric violence" (Shrivastava \& Sivakami, 2020) where a pregnant woman from Jharkhand was reportedly mistreated, deprived of medical help, and told to clean her own blood on visiting a government hospital. This particular instance of dehumanizing treatment by the medical staff towards the Muslim woman reveals the communal habitus that thrives in the country extending its bias and hatred to the minorities. It also reflects on the nuanced issue of a woman's lack of autonomy during labor and the deliberate lack of medical support that caused the woman to lose her baby and impinged on her a sense of trauma. A young pregnant woman from Madhya Pradesh lost her life after being denied medical attention in a government hospital and her condition deteriorated due to the unnecessary movement from one hospital to another private nursing home, ultimately claimed her life (Shrivastava \& Sivakami, 2020). The country reported approximately 20.1 million births between March to December, 2020 which clearly indicates that majority of them had been deprived of the required prenatal care and routine check-up due to the movement restrictions and fear of getting infected. Telephonic and online consultation in such moments can effectively guide women during their pregnancy and also those with unwanted pregnancies (Jungari, 2020) by providing information about required facilities, transport mediums, help them in home monitoring and also extend the essential emotional and social support for alleviating depression in such critical junctures (Aggarwal, Sharma \& Guleria, 2021).

While India battles the dual crisis- the visible outbreak of the Covid-19 and the lurking social adversity related to 'shadow pandemic', the role of teleconsultation and telepsychiatry in extending psychosocial support in both cases remains significant. To help women deal with the sense of extreme stress, physical violence, and psychological abuse amidst the pandemic, World Health Organization came forward advising health providers across all nations to take adequate steps in utilizing telemedicine to identify and address any form of violence that they are experiencing. The initial form of support in times of restricted movement can be offered through empathetic telephonic conversations, thereby inquiring about the specific needs of the victim, assuring her safety, and connecting survivors to proper support services (WHO, 2020). The usage of social media platforms to spread awareness and promote solidarity also remains crucial in 
the context and an advertisement related to the online campaign \#LockdownOnDomesticViolence featuring Indian actors/actresses and cricketers became quite popular in soliciting collectivization against the social extremity. The police department in Raipur, Chattisgarh came up with an innovative campaign named "Chuppi Tod" (Break the Silence), and through the helpline numbers, there were able to provide assistance to the victims and survivors of domestic exploitation. The police team also received complaints from other states like Uttar Pradesh, Gujarat, and Rajasthan and besides informing the local police of the individual state to investigate the matter, they also extended telephonic counseling (Drolia, 2020). In Uttar Pradesh, the police launched an emergency helpline number to deal with women facing domestic abuse, and the initiative was named "Suppress corona, not your voice". The campaign being online featured a woman wearing a mask, which clearly indicated that the purpose of the mask is to protect oneself from the virus and not to suppress the voice of those facing regular torture in their homes during the lockdown (Panicker, 2020). The Department of Psychiatry of the National Institute of Mental Health and Neurosciences, Bengaluru laid down some basic guidelines for conducting tele sessions efficiently with women falling prey to violence. The presence of the abusers at home can make conversation difficult and safety can be threatened, hence it is of prime importance to assess the situation and ask the victim to answer in 'yes' or 'no'. Also, code words can be used and if there lies any imminent threat then the person should be advised to reach out to the neighbor or friend if possible. In case of continued exploitation, the victim was instructed to directly contact the police or National Commission for Women-domestic violence helpline numbers (Chandra, 2020). Despite fearing retaliation and social stigma, the pandemic did strengthen the informal networks like Whatsapp-based groups, emails, online complaint links, and others (Rawat, 2020), thereby creating an alternative channel for women to register their unheard cases of abuse and seek redressal. Telecommunication thus helped in addressing the "gendering of pandemic vulnerabilities", (Hans et al., 2021, p. 4) intervening in immediate distress in households and providing therapeutic intervention in matters related to mental health like anxiety, alienation, verbal abuse (name calling, derogatory remarks, invalidating feelings, spiteful inaction, emotional abandonment) and helping victims to deal with physical stressors like abusive relationships, threatening/manipulative behaviours, sexual violence and others. The physical as well as the psychological adversities impelled by Covid-19 has underscored the efficacy of health communication through telephonic and online mediums promoting healing, enabling selfawareness and encouraging societal change.

1.4 Role of Teleconsultation in Geriatrics Care With the SARS-Cov-2 virus unfolding its detrimental self, the country also experienced the inflaming of aggression and abuse on the domestic fronts and besides women and children, elders were also harassed on different grounds. The 2011 Census, reported that $8.6 \%$ of the Indian population comprises the elderly generation and the striking facet that emerges in the Indian context is the aspect of eldercare in the country that remains intertwined within the intergenerational family where caregiving has often been correlated with the successive generations in the family. Besides contributing to $53 \%$ of the reported fatalities in the nation (Chari, 2021), the pandemic and its consequential lockdown exacerbated the mental health of these vulnerable people. The common forms of abuse meted out towards the elderly beings during the Covid-19 outbreak are wideranging- physical abuse, psychological abuse, financial exploitation, verbal abuse, abandonment, unreasonable confinement, neglect that comprises both self-neglect (when the elderly being is not able to look after himself/herself properly) (Rochester ElderLaw.com, 2021) and neglect of caregivers, denying proper quantity of food, communication, care, and respect. Findings suggest that almost $77.5 \%$ experienced verbal abuse, 52\% were prone to neglect, $28.5 \%$ financially exploited and $27.3 \%$ faced physical abuse during the first wave of the pandemic (Longitudinal Ageing Study in India (LASI), 2020). The national crisis has increased the dependency of the older people on the caregivers (Han, 2020) who felt the dire economic pressure and the limited availability of resources was a serious cause of stress and the care recipients often became the soft target 
of physical/emotional assaults (Malik, Burhanullah, \& Lyketsos, 2020). Domestic abuse was reported and particularly old women were at the receiving ends of physical maltreatment. In Punjab and Haryana, disturbing cases were reported during the pandemic where an 80-year-old ailing mother was found in a pit left abandoned by her two sons, an 85 year- old women being considered inauspicious by her family was confined to a small room, another woman aged 82 years was mercilessly beaten by her daughter-inlaw. In another horrifying situation, a 55-yearold woman even tried ending her life by jumping into the well to save herself from the brutalities of her son and daughter-inlaw (Sehgal, 2020). In most cases, the local police informed that parents were hesitant to speak about their experienced abuse and were also ignorant about the laws meant to protect them from such appalling and dehumanizing occurrences. Non-profit organizations like HelpAge India and Nightingales Medical Trust have come forward in extending their valuable help through helpline numbers to those suffering from old age issues, abuse, stigma, and other psycho-social distress. Bengaluru received over 1,245 calls between January to August 2020 in contrast to 515 calls reported in 2019, and elderly citizens sought varied kinds of assistance ranging from family harassment to the inability to purchase necessary medicine and grocery (Kalkod, 2020).

In such daunting times, however, senior people have been quite responsive in adopting technological means like e-commerce apps, social networking sites, and other gadgets to procure items of daily necessity and to alleviate their loneliness. Tapan Mishra, the cofounder of the Pune based organization, Seniority that deals in health and lifestyle products for older citizens observed that there has been an apparent rise during the lockdown in the usage of technology, virtual platforms, and telecommunication means for ensuring safety and also to voice their concerns (HealthCareRadius, 2020). The organization in collaboration with RPG Life Sciences also launch a monitoring app called "SafeSeniors" that aided the aged beings to keep track of their health conditions (Awasthi, 2020). HelpAge India, a non-profit organization providing aid to disadvantaged sections of elderly citizens in the country, extended their help to the abandoned old people on the streets and support to those battling emotional/physical abuse at home during the lockdown. Their National Elders Helpline remains active across 21 states in India providing e-medical assistance, legal aid in case of extreme torture, telephonic counseling in depressive situations, and other necessary service-related information. Despite the amplification of existing ageist prejudices like the ongoing social media trend \#BoomerRemover along with disparaging memes by the younger population that has vehemently reinforced the discrimination related to ageism (Malik, Burhanullah, \& Lyketsos, 2020), digital media has ensured to circulate awareness amongst people to step forward and protect the most neglected lives. A joint initiative by New Delhi Television (NDTV) and HelpAge India with the trending hashtag \#SaveOurSeniors raised funds for helping the numerous aged residents in the country who were simply struggling to survive through the difficult times (Save Our Seniors, 2020). Despite the existing digital divide, physical appointments to doctors decreased by $32 \%$ whereas a three times increase was recorded in the usage of online and teleconsultations (Varghese, 2020). Teleconsultation with medical experts thus offered the necessary assistance in emergency situations requiring palliative care and online counselling with mental health experts helped the elderly population cope with feelings of anxiety, loneliness, and depression.

\subsection{Practical Implications}

The above discussion underlines how teleconsultation has emerged as a pronounced need in the contemporary crisis situation which besides providing aid and support also investigates into the relevant wider context of the victim's experience correlated with the family environment, childhood adversities, economic fallout, and available networks of social support. Bridging the gap between doctors/counsellors and patients/victims, telecommunication has removed the infrastructural challenges that have surfaced during the crisis and have enabled those facing distress in getting consultations. The $24 \times 7$ emergency helpline numbers have come to the rescue and mitigate the sufferings of women and elderly citizens inside their homes. 
A psycho-social counselling service named iCALL, developed by Tata Institute of Social Sciences, India in 2012 deserves a mention for its relentless service during the crucial months of the virus outbreak. Its Covid line continued addressing varied health issues by extending professional outreach and created awareness on social, psychological, and allied issues both at the micro and meso levels (Joshi, 2021). As normalcy got disrupted, strict restrictions on movement were imposed and physical distancing was considered effective to curb the transmission of the virus, therapists and medical practitioners adapted to technology based mediums and iCALL rendered its valuable psycho-social support during the pandemic in different states like Maharashtra, Rajasthan, Madhya Pradesh, Odisha, and Bihar. Realising that the restrictions on mobility and home confinement might make women, girls and children more susceptible to acts of physical, sexual and emotional harm, iCALL's initiative delivered extensive support to build resilience and self-care practices through a participatory and empowerment based approach.

Thus, understanding the gendered effects of the Covid-19 pandemic in the Indian context would remain incomplete if one does take into consideration the plight of the women including widows and aged females in the domestic fronts. On analysing the practical implications associated with teleconsultation in assuaging gender related abuse, one recognizes how it effectively encourages interaction between individuals irrespective of the physical distance thereby building a strong network manifesting succour and aid. As Covid has pronounced the need to re-engage with the efficacy of the existing laws of the country related to women's rights and safety, it is important for policy makers to focus on framing guidelines and norms that would serve the needs of women in such crucial junctures of crisis. There also exists a need to familiarize the female citizens with telemedicine and online consultation practices for seeking solutions/help in times like the pandemic when the traditional in-person care would not be feasible.

\subsection{CONCLUSION}

While India attempts to resuscitate herself from the noxious effects of the pandemic, the country will encounter several deterrents pertaining to the economic and psycho-social factors. Mental health in this particularly stressed backdrop will be the fertile space for arousing depression, panic, and, self-harm and aggravating economic disparities, alcoholism, domestic violence, and elder abuse. To deal with such menace, possible steps should be taken to adopt an effective and integrated response for addressing the violence in the public and domestic spaces that has additional effects on certain marginalized sections of the society like women, children, elderly, migrant workers, underprivileged (Joshi, 2021). The "psychosocial trauma" (Joshi, 2021, p. 3) arising from experiencing abuse for a prolonged period in a lockdown can have lasting effects on an individual's life living him/her emotionally scarred. After the government enforced the lockdown in India, some fundamental guidelines (Mental Health in the times of COVID-19 Pandemic: Guidance for General Medical and Specialised Mental Health Care Settings, 2020; Telemedicine Practice Guideline, 2020) were established for conducting telephonic psychotherapy to enable the uninterrupted functioning of mental health and emergency services. With approximately $66 \%$ of India's population inhabiting rural areas where internet access is minimal ("How the Digital Divide Affects Poverty in India Amid COVID-19", 2021) and numerous lacking a smartphone, telephone communication became the potent medium to provide an inclusive manner of counselling. Telepsychiatry has been competently used during the ongoing pandemic to deal with anxiety disorder, empty nest syndrome ${ }^{3}$, cabin fever, panic-attack, and varied psychological issues and revamping intervention in extreme conditions. The current condition has paved the path for an active engagement of telehealth and teleconsultation in India focusing on integrated development of the health system. The requirement for better "health at a distance" (Eren \& Webster, 2016, p. 28) has supported the adoption of telemedicine which enabled the masses to stay connected through mobile health services and has successfully reduced the burden of the primary healthcare system. It has also emerged as an important tool for facilitating research on both epidemiological and psycho-social grounds and its wider acceptance will assist us in bracing ourselves for any future pandemics and simultaneously strengthen support 
networks to tackle gender and age-related abuse.

\section{Notes}

1. A psychological condition that may arise when an individual is confined to his/her house for an extended period. Feelings of loneliness, anxiety, irritability, restlessness are the common symptoms associated with cabin fever syndrome. The Covid-19 restrictions have limited movement along with social interaction and the physical isolation has caused an increase in the experiencing of cabin fever.

2. The term 'Shadow pandemic' addresses the growing incidence of violence against women and girls during the outbreak of Covid-19. Gender-based violence has emerged as a parallel crisis across the world when women confined to their homes have limited ability to voice their complaints and seek help for different kinds of abuse. Thus invisible to the public eye, the repeated exploitation of women on various grounds during the pandemic requires immediate governmental and community intervention for supporting the victims and the survivors.

3. Empty nest syndrome is a psychological condition that is associated with pain and grief when one's children move out of the homes and travel to other cities/countries for academics or job opportunities. This depressive condition is commonly found in elderly women who are regarded as the primary caregiver in the family as they suffer the most when the performance of certain prescriptive roles of motherhood comes to a halt when the children grow up and live their individual lives outside the boundaries of home.

\section{REFERENCES}

Aggarwal, R, Sharma, A, \& Guleria, K. (2021). Antenatal care during the pandemic in India: the problem and the solutions. International Journal of Pregnancy and Child Birth, 7 (1), 15-17. DOI: $10.15406 / \mathrm{ipcb} .2021 .07 .00220$.

Aneja, J \& Arora, S. (2021). Telemedicine and ethics: opportunities in India. Indian Journal of Medical Ethics. DOI: https://doi.org/10.20529/IJME.20 $\underline{21.042}$
Asrani, P., Eapen, M.S., Hassan, Md. I., \& Sohwal, S.S. (2021). Implications of the second wave of COVID-19 in India. The Lancet Respiratory Medicine, 9 (9), 9394. https://doi.org/10.1016/S22132600(21)00312-X

Awasthi, P. (2020, April 10). Newly launched 'SafeSeniors' app to monitor senior citizens amid Covid-19 crisis. Business Line.

https://www.thehindubusinessline.co $\mathrm{m} /$ news/variety/newly-launchedsafeseniors-app-to-monitor-seniorcitizens-amid-covid-19crisis/article31305525.ece

Bandopadhyay, S. \& Maity, B. (2021). Covid19 Pandemic: Implications for Widowed and Elderly Women in India. In $\mathrm{R}$. Bhattacharya, et al. (Eds.), The Covid-19 Pandemic, India and the World: Economic and Social Policy Perspectives (pp. 309320). London: Routledge.

Bhattacharya, R., Dastidar, A.G. \& Sikdar, S. (2021). The Covid-19 Pandemic, India and the World: Economic and Social Policy Perspectives. London: Routledge.

Borgen Magazine. (2021, March 03). How the Digital Divide Affects Poverty in India Amid

COVID-19. https://www.borgenmagazine.com/di gital-divide-in-india/

Chandra, J. (2020, April 10). NCW launches domestic violence helpline. The Hindu. https://www.thehindu.com/news/nati onal/ncw-launches-domestic-violencehelpline/article31312219.ece

Chang, E-Shien \& Levy, Becca R. (2021). High Prevalence of Elder Abuse During the COVID-19 Pandemic: Risk and Resilience Factors. American Association for Geriatric Psychiatry. https://doi.org/ 10.1016/j.jagp.2021.01.007

Chari, Harshita. (2021, January 11). Survey Finds One in 20 of India's Elderly Was Ill-Treated in 2020. The Wire. https://science.thewire.in/health/surv ey-finds-one-in-20-of-indias-elderlywas-ill-treated-in-2020/.

Charmaz, K. (1999). Stories of suffering: Subjective tales and research narratives. Qualitative Health Research, 9, 362-382. 
Coronavirus lockdown | Over 50 helplines set up across India to help women facing domestic violence. (2020, April 18). The Hindu.

https://www.thehindu.com/news/nati onal/coronavirus-lockdown-over-50helplines-set-up-across-india-to-helpwomen-facing-domesticviolence/article31376933.ece

Das, Manob, Das, Arijit, \& Mandal, Ashis. (2020).Examining the impact of lockdown (due to COVID-19) on Domestic Violence (DV): An evidences from India. Elsevier Public Health Emergency Collection. https://www.ncbi.nlm.nih.gov/pmc/ar ticles/PMC7413053/

Dinakaran, D., Manjunatha, N., Kumar, C.N. \& Math, S.B. (2021). Telemedicine practice guidelines of India, 2020: Implications and challenges. Indian Journal of Psychiatry, 63 (1), 97-101. doi: $10.4103 /$ psychiatry.IndianJPsychiatry_4 $\underline{76 \_20}$

Domestic violence on the rise during lockdown, 69 complaints since 24 March: NCW. (2020, April 2). The Print. https://theprint.in/india/domesticviolence-on-the-rise-during-lockdown69-complaints-since-24-marchncw /393730/

Domestic violence cases in India on the rise during lockdown, says report. (2020, May 18). The Times of India. https://timesofindia.indiatimes.com/lif e-style/relationships/lovesex/domestic-violence-cases-in-indiaon-the-rise-during-lockdown-saysreport/articleshow/75801752.cms

Drolia, Rashmi. (2020, May 13). Raipur police's 'Chuppitod' campaign to deal with domestic violence survivors. The Times of

India.https:/ / timesofindia.indiatimes.co $\mathrm{m} /$ city/raipur/raipur-polices-

chuppitod-campaign-to-deal-withdomestic-violencesurvivors/articleshow/75714642.cms

Elderly, differently-abled, widows to get 3 months' pension in advance. (2020, April 08). The Economic Times. https://economictimes.indiatimes.com/ wealth/personal-finance-news/elderly- differently-abled-widows-to-get-3months-pension-inadvance/articleshow/74847650.cms.

Eren, H. \& Webster, J.G. (2016). The Medicine and Electronic Medicine. Boca Raton: CRC Press, Taylor and Francis Group.

Gandhi, Urvashi. (2020, April 14). COVID-19: "How is the global pandemic threatening the safety of women and girls. Hindustan Times. https://www.hindustantimes.com/sexand-relationships/covid-19-how-is-theglobal-pandemic-threatening-the-safetyof-women-and-girls/storyiVGTsCnwnyLL05xTIuQRsL.html

Gauttam, P., Patel, N., Singh, B., Kaur, J., Chattu, V.K., Jakovljevic, M. (2021). Public Health Policy of India and COVID-19: Diagnosis and Prognosis of the Combating Response. Sustainability, 13 ,

3415. https://doi.org/10.3390/su13063415

Han, S. Duke, \& Mosqueda, Laura. (2020). Elder Abuse in the Covid-19 Era. Journal of the American Geriatrics Society,13861399.

https://agsjournals.onlinelibrary.wiley. com/doi/10.1111/igs.16496

Hans. A, Kannabiran.K, Mohanty.M, \& Pushpendra. (2021). Migration, Workers, and Fundamental Freedoms: Pandemic Vulnerabilities and States of Exception in India. London: Routledge.

Health Care Radius. (2020. November 26). Senior citizens warm up to telemedicine during COVID-19. https://www.healthcareradius.in/techn ology/27211-senior-citizens-warm-upto-telemedicine-during-covid-19

Joshi, Aparna. (2020). COVID-19 pandemic in India: through psycho-social lens. Journal of Social and Economic Development.

https://doi.org/10.1007/s40847-02000136-8

Jungari, S. (2020). Maternal mental health in India during COVID-19. Elsevier Public Health Emergency Collection, 185, 97-98. doi: 10.1016/j.puhe.2020.05.062.

Kalkod, Rajiv. (2020, September 19). Bengaluru: $250 \%$ rise in calls to elders' 
helpline during pandemic. The Times of India.

https://timesofindia.indiatimes.com/cit $\mathrm{y} /$ bengaluru/bengaluru-250-rise-incalls-to-elders-helpline-duringpandemic/articleshow/78199629.cms

Kumar, Rana \& Rana, Majesh. (2020, June 3). Lockdown reinforced gender roles, more women abused. Deccan Chronicle. https://www.deccanchronicle.com/opi nion/columnists/030620/lockdownreinforced-gender-roles-more-womenabused.html

Lal, Neeta. (2020, April 17). India's 'Shadow Pandemic': Domestic violence in India surges during the COVID-19 crisis. The Diplomat.

https://thediplomat.com/2020/04/indi as-shadow-pandemic/

Longitudinal Ageing Study in India (LASI), Wave-1. (2020). Ministry of Health and Family Welfare, Government of India, New Delhi.

Malik. M, Burhanullah. H \&, Lyketsos. C.G. (2020, September 30). Elder Abuse and Ageism during COVID-19. Psychiatric Times.

https://www.psychiatrictimes.com/vie w/elder-abuse-and-ageism-duringcovid-19

Mental Health in the times of COVID-19 Pandemic: Guidance for General Medical and

National Institute of Mental Health \& Neurosciences, Bengaluru, India.

O'Leary, K. D., \& Maiuro, R. D. (Eds.). (2001). Psychological abuse in violent domestic relations. New York: Springer Publishing Company.

Pandit, Ambika. (2020, June 15). Abuse has increased during lockdown, say $71 \%$ of elderly. The Times of India. https://timesofindia.indiatimes.com/in dia/abuse-has-increased-during-

lockdown-say-71-of-

elderly/articleshow/76377324.cms

Panicker, Lalita. (2020, April 4). The lockdown is making women more vulnerable. Hindustan Times. https://www.hindustantimes.com/colu $\mathrm{mns} /$ the-lockdown-is-making-women- more-vulnerable-opinion/story-

C5MchD5I3fzghxKeHL4olI.html

Paredes, M. R., Apaolaza, V., FernandezRobin, C., Hartmann, P., \& YañezMartinez, D. (2020). The impact of the COVID-19 pandemic on subjective mental well-being: The interplay of perceived threat, future anxiety and resilience. Elsevier Public Health Emergency Collection. doi:10.1016/j.paid.2020.110455

Radhakrishnan.V, Sen.S \& Singaravelu,N. (2020, June 20). Domestic violence complaints at a 10-year high during COVID-19 lockdown. The Hindu. https://www.thehindu.com/data/data -domestic-violence-complaints-at-a-10year-high-during-covid-19lockdown/article31885001.ece

Ratnam, Dhamini. (2020, April 26). Domestic violence during Covid-19 lockdown emerges as serious concern. 26 April, $2020 . \quad H i n d u s t a n$ Times. https://www.hindustantimes.com/indi a-news/domestic-violence-duringcovid-19-lockdown-emerges-as-seriousconcern/storymMRq3NnnFvOehgLOOPpe8J.html

Ravindran, S. \& Shah, M. (2020). Unintended Consequences of Lockdowns: Covid-19 and the Shadow Pandemic. NBER Working Paper Series, 1- 43. https://www.nber.org/system/files/w orking_papers/w27562/w27562.pdf

Rawat, N.R. (2020, May 4). Making Homes Safer For Women During Covid-19. NITI Aayog, Government of India. https://niti.gov.in/making-homessafer-women-during-covid-19

RochesterElderLaw.Com. (2021, February 16). Elder Abuse during the Coronavirus Pandemic.

https://rochesterelderlaw.com/elderabuse-during-the-coronaviruspandemic/

Sanderson, C. (2008). Counselling Survivors of Domestic Abuse. London: Jessica Kingsley Publishers. Medical Council of India and NITI Aayog, India.

Save Our Seniors. HelpAge India \& NDTV. https://special.ndtv.com/save-ourseniors-68/donate-now 
Sehgal, Manjeet. (2020, August 25). Tragic tales: Cases of elderly abuse surface in Punjab, Haryana in times of Covid. India Today.

https://www.indiatoday.in/india/stor y/tragic-tales-cases-of-elderly-abusesurface-in-punjab-haryana-in-times-ofcovid-1714723-2020-08-25.

Sharpe, Albie. (2019). Public Health and Patriarchy: Militarism and Gender as Determinants of Health Security. In Reardon, Betty A. and Hans, Asha. The Gender Imperative: Human Security vs State Security, 2nd ed. London: Routledge, 335-365.

Shrivastava, Surbhi \& Sivakami. M. (2020, April 23). Obstetric Violence During COVID-19 Is yet Another Challenge for Indian Women. The Wire. https://thewire.in/rights/womencovid-19-obstetric-violence

Sonawane, Santosh. (2021, April 21). Relatives watched helplessly as patients died gasping for breath.The Times of India. https://timesofindia.indiatimes.com/cit $\mathrm{y} /$ nashik/relatives-watched-helplesslyas-patients-died-gasping-forbreath/articleshow/82185539.cms.Speci alised Mental Health Care Settings. (2020). Department of Psychiatry,

Telemedicine Practice Guideline: Enabling Registered Medical Practitioners to Provide Healthcare Using Telemedicine. (2020).

The Elders. (2020, November 27). Four areas of action to tackle the shadow pandemic of violence against women. https://theelders.org/news/four-areasaction-tackle-shadow-pandemicviolence-against-women
Thompson, T.L, Dorsey, A.M, Miller, K, \& Parrott, R. (2003). Handbook of Health Communication. New Jersey: Lawrence Erlbaum Associates, Inc. Publishers.

Tomar, R. \& Mohanty, P.C. (2020, October 19). Tackling the shadow Pandemic of rising domestic violence. The New Indian Express.

https://www.newindianexpress.com/o pinions/2020/oct/19/tackling-theshadow-pandemic-of-rising-domesticviolence-2212123.html

United Nations Office on Drugs and Crimes.. (2020, November 24). What crime and helpline data say about the impact of the COVID-19 pandemic on reported violence against women and girls. https://www.unodc.org/documents/d ata-and analysis/covid/Violence_against_wome n_24Nov.pdf

Vahali, H. O. (2021). Psychosocial Challenges in the Midst of the Coronavirus. In India and the Pandemic: The First Year. Edited by Reddy, C. Rammanohar. Hyderabad: Orient Blackswan Private Limited.

Varghese, A.S. (2020, July 19). Tele-counselling assuages emotional, psychological issues in Covid patients. The New Indian Express. $\quad$ https://www.newindian express.com/cities/kochi/2020/jul/19/ tele-counselling-assuages-emotionalpsychological-issues-in-covid-patients2171751.html

World Health Organization. (2020, April 7). COVID-19 and violence against women: What the health sector/system can do. https://apps.who.int/iris/bitstream/ha ndle/10665/331699/WHO-SRH-20.04eng.pdf?ua=1 